\title{
Laser valvotomy with balloon valvoplasty for pulmonary atresia with intact ventricular septum: five years' experience
}

John L Gibbs, Michael E Blackburn, Orhan Uzun, David F Dickinson, Jonathan M Parsons, Ranjit R Chatrath

\begin{abstract}
Objective-To assess immediate and medium term results of transcatheter laser valvotomy with balloon valvoplasty in selected infants with pulmonary atresia and intact ventricular septum.

Design-Prospective study.

Setting-Tertiary cardiac unit.

Patients-All infants with pulmonary atresia and intact septum with no more than minor tricuspid valve hypoplasia referred between November 1990 and June 1995. Laser valvotomy was attempted in nine infants of median age $4 \cdot 5$ days and median weight $3.6 \mathrm{~kg}$.

Intervention-The pulmonary valve was perforated using a 0.018 inch fibreoptic guidewire attached to a NdYag laser and introduced through a catheter positioned beneath the valve. After perforation the valve was dilated with progressively larger balloons.

Main outcome measures-Successful laser valvotomy and balloon dilatation, complications, pulse oximetry, right ventricular outflow velocities, and need for surgical treatment.
\end{abstract}

Results-Valvotomy was successful in all but one case, the failure being due to laser breakdown. After perforation the valve was dilated to 6-8 $\mathrm{mm}$ diameter. Prostaglandin $E$ was withdrawn immediately in six of the eight duct dependent infants, and 28 and 49 days later in two. No patient required an aortopulmonary shunt. Two patients had repeat valvoplasty at 20 days and three months of age, respectively; one required infundibular resection and closure of the atrial septum at age four and one is awaiting similar treatment.

Conclusions-Laser valvotomy with balloon valvoplasty is safe and effective treatment for selected patients with pulmonary atresia and intact ventricular septum and should be considered as first line treatment in place of surgical valvotomy.

(Heart 1997;77:225-228)

Leeds West Yospital,

Leeds, West Yorkshire

J L Gibbs

M E Blackburn

O Uzun

D F Dickinson

J M Parsons

R R Chatrath

Correspondence to:

Dr J L Gibbs, Department of Paediatric Cardiology, Pillingbeck Hospital, York

Road, Leeds LS14 6 UQ.

Accepted for publication

19 November 1996
Transcatheter laser valvotomy for pulmonary atresia was first reported in $1991 .^{1}$ Early experience in patients with and without ventricular septal defects showed that the technique held some promise ${ }^{23}$ but it attracted negative criticism $^{4}$ because of the associated risk of potentially life threatening complications such as cardiac perforation, although such risks occurred mainly in patients with ventricular septal defects or with infundibular atresia. We report our experience, over a five year period, of laser valvotomy in a selected group of patients with pulmonary atresia and intact ventricular septum.

\section{Methods}

PATIENTS

Over a four year period all patients referred with pulmonary atresia, an intact ventricular septum, a tripartite right ventricle, and no more than moderate hypoplasia of the right ventricle were treated by laser valvotomy as first line treatment, informed consent being obtained from the child's parents in each case. Their ages ranged from 0.5 to 70 days (median 4.5) and their weights ranged from $2 \cdot 1$ to $4.7 \mathrm{~kg}$ (median 3.6 ). Eight of the nine infants were duct dependent and were treated with prostaglandin $\mathrm{E}$ infusions. Informed consent for the procedure was obtained from each child's parents but in the light of an earlier report of the technique ${ }^{1}$ we did not seek formal ethics committee approval.

\section{PROCEDURES}

Initial assessment

A crude echocardiographic estimate of the capability of the right ventricle to support the pulmonary circulation was made by visual comparison of right and left ventricular cavity sizes and the diameters of the tricuspid and mitral valves. Detailed morphometric measurements of the ventricles were not made. Pulmonary valve diameter was measured echocardiographically to assist in the choice of valvoplasty balloon size.

\section{Laser valvotomy and balloon valvoplasty}

Cardiac catheterisation was carried out under general anaesthetic in eight cases, and using local anaesthetic, ventilation, and sedation with morphine in one case. Percutaneous femoral venous access was used in every case; no arterial catheters were used. Digital subtraction left ventriculograms was obtained in the right anterior oblique and left lateral projections to opacify the pulmonary trunk through the arterial duct. A $4 \mathrm{~F}$ or $5 \mathrm{~F}$ Cobra catheter was positioned in the right ventricular outflow tract immediately beneath the pulmonary valve and the catheter position and the 
Right anterior oblique angiograms in an eight day old, $3.6 \mathrm{~kg} \mathrm{baby}$ (patient 6), (A) of the right ventricle, showing the position of the atretic pulmonary valve (arrowed); (B) of the left ventricle, showing the pulmonary trunk (arrowed) filling retrogradely through the arterial duct; and $(C)$ of the right ventricle after laser valvotomy and serial dilatation of the pulmonary valve up to $10 \mathrm{~mm}$ diameter.
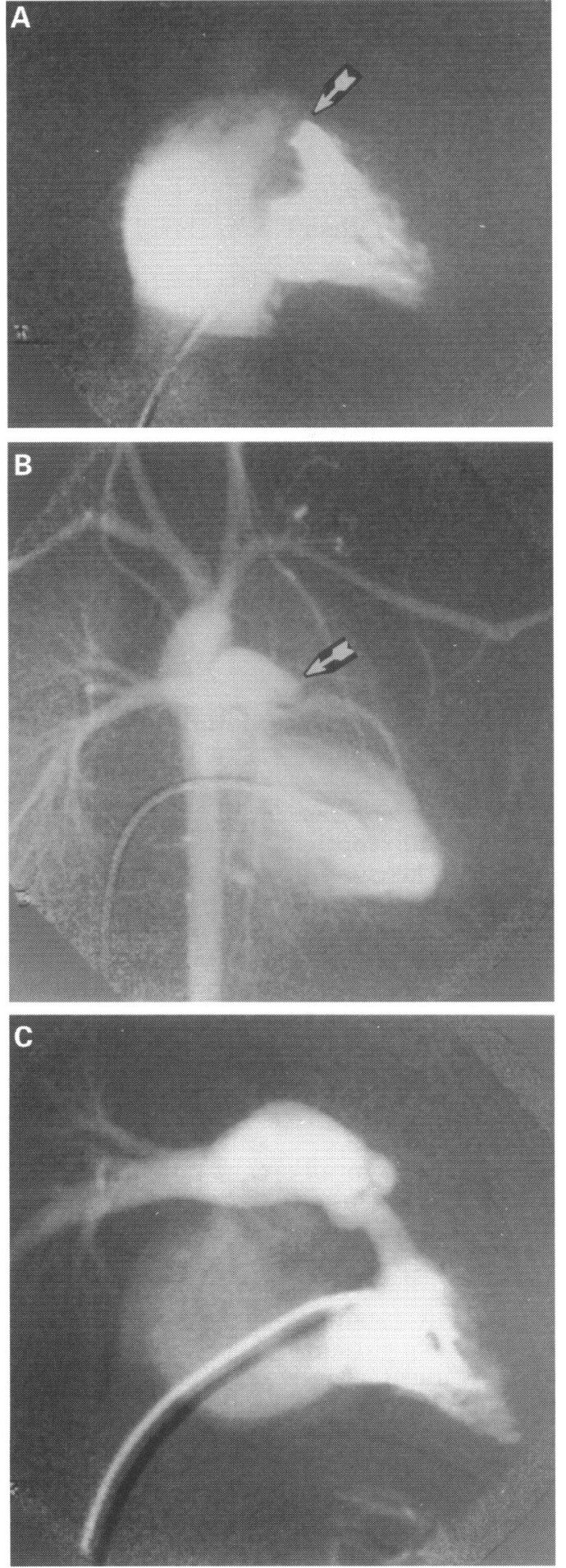

direction of its tip were adjusted with the aid of frozen images of the pulmonary trunk in two planes. Hand injections of contrast were given immediately below the valve to ensure that it was atretic rather than very severely stenosed. A 0.018 inch $(0.7 \mathrm{~mm})$ fibreoptic guidewire (Trimedyne, APC Cardiovascular Ltd) was advanced to the tip of the Cobra catheter and its proximal end was connected to an Nd-YAG laser generator (Trimedyne, Cardiolase 4000). During gentle forward pressure on the guidewire, the laser was fired in continuous wave mode for periods of between five and eight seconds until the wire perforated the valve and advanced into the pulmonary trunk. Appropriate eye protection was provided for staff present in the laboratory during laser firing.

Following valve perforation either the fibreoptic wire itself or a stiffer 0.018 inch exchange wire (Flex-T, Vascular Ltd) was advanced into a distal branch pulmonary artery or into the descending aorta through the arterial duct. The Cobra catheter was then exchanged for a 3.5 or $4 \mathrm{~mm}$ diameter coronary angioplasty balloon catheter (Cordis Optima, Cordis Olympix, or Baxter Intrepid). After dilatation with the coronary angioplasty balloon, the valve was dilated further with a $\frac{\infty}{2}$ balloon of diameter up to $120 \%$ of the $\propto$ echocardiographically estimated pulmonary o valve diameter. The patients' exposure to radi- $\overrightarrow{0}$ ation was assessed by recording both fluoroscopy time and the number of angiograms $\vec{\omega}$ performed. A representative case is shown in the figure.

\section{Follow up}

Prostaglandin E was discontinued immedi- N ately after the procedure was completed. Pulse 을 oximetry was monitored closely while the arte- $]$ rial duct was closing and prostaglandin $\mathrm{E}>$ treatment was restarted if marked desaturation (below 50\%) occurred. Repeated attempts to $\stackrel{\rho}{工}$ withdraw the drug were made until right ven- $\overrightarrow{0}$ tricular compliance improved such that the circulation was no longer duct dependent. Right ventricular outflow velocities and oxygen saturation were measured when the duct $\bar{\partial}$ closed. The infants were discharged from hospital after ductal closure. Further outpatient $\stackrel{\varnothing}{\varnothing}$ follow up included clinical examination, $\vec{\Rightarrow}$ echocardiography, pulse oximetry when possi- 응 ble, and-where appropriate-repeat cardiac $₹$ catheterisation with further dilatation of the pulmonary valve.

\section{Results}

The pulmonary valve was successfully perforated in all but one case, the failure being due to laser generator breakdown. This patient had 0 a successful surgical valvotomy. In the eight successful cases between one and three laser $\frac{}{2}$ firings of between three and five seconds at a power output of between $3 \mathrm{~W}$ and $5 \mathrm{~W}$ were $\Omega$ required to perforate the pulmonary valve. 0 Serial balloon dilatation after valve perforation proved relatively straightforward, tracking of 0 the balloon catheter being particularly smooth 0 if the guidewire could be advanced across the $\frac{C}{\Phi}$ arterial duct into the descending aorta, such $\stackrel{\infty}{+}$ that the stiffest part of the wire was positioned 0 across the right ventricular outflow tract. No $\stackrel{\vec{D}}{0}$ untoward effects were encountered in relation $\stackrel{\bigcirc}{9}$ to a wire being positioned through the arterial $\stackrel{\square}{\square}$ duct. None of the patients had evidence of significant coronary artery abnormalities or right 8 ventricular sinusoids.

Radiation exposure is summarised in table 1 . Between two and six (median 3.5) digital sub- 구 traction angiograms were required, fluoroscopy time ranging from 11.3 to 98 minutes (median 30.5).

After withdrawal of prostaglandin $\mathrm{E}$, two of 
Table 1 Radiation exposure

\begin{tabular}{lllll}
\hline Patient & $\begin{array}{l}\text { No of } \\
\text { angiograms (DSA) }\end{array}$ & $\begin{array}{l}\text { Fluoroscopy } \\
k V\end{array}$ & $\begin{array}{l}\text { Fluoroscopy } \\
m A\end{array}$ & $\begin{array}{l}\text { Fluoroscopy time } \\
(\text { min) }\end{array}$ \\
\hline 1 & 3 & 75 & $1 \cdot 7$ & $18 \cdot 5$ \\
2 & 4 & 70 & $1 \cdot 4$ & 98 \\
$3^{\star}$ & 4 & 81 & $2 \cdot 1$ & $11 \cdot 3$ \\
4 & 6 & 76 & $1 \cdot 8$ & 32 \\
5 & 4 & 72 & $1 \cdot 6$ & 20 \\
6 & 5 & 72 & $1 \cdot 6$ & 36 \\
7 & 2 & 60 & $1 \cdot 0$ & 30 \\
8 & 3 & 64 & $1 \cdot 0$ & $18 \cdot 7$ \\
9 & 4 & 60 & $0 \cdot 8$ & $30 \cdot 7$ \\
Mean & 4 & 70 & $1 \cdot 4$ & $32 \cdot 8$ \\
\hline
\end{tabular}

${ }^{\star}$ In patient 3 the procedure was abandoned because the laser failed to fire. DSA, digital subtraction angiography.

the eight patients became severely cyanosed over the following two days as the arterial duct closed, pulse oximetry showing oxygen saturations below $50 \%$. These two patients required reinstatement of treatment with prostaglandin $\mathrm{E}$, one child remaining duct dependent for 49 days and the other for 28 days. The patient who was duct dependent for 49 days, who had initial balloon dilatation to a diameter of only $5 \mathrm{~mm}$ (he weighed $2 \cdot 1 \mathrm{~kg}$ and had a relatively small pulmonary trunk), had a repeat dilatation of the pulmonary valve to a diameter of 8 $\mathrm{mm}$ at the age of 20 days, 19 days after his laser valvotomy. None of the patients who had a successful laser valvotomy required an aortopulmonary shunt.

Right ventricular outflow velocities and oxygen saturations early after ductal closure and at follow up are summarised in table 2 . Right ventricular outflow velocities measured early after ductal closure ranged from 1.5 to $3.8 \mathrm{~m} / \mathrm{s}$ (median $2.5 \mathrm{~m} / \mathrm{s}$ ) and oxygen saturations ranged from $60 \%$ to $90 \%$. Right ventricular outflow velocities increased with follow up in three of the eight patients. Oxygen saturations tended to increase with time as right ventricular hypertrophy regressed, but four patients (including the three with increasing outflow velocities) remained mildly cyanosed at latest follow up (before any surgical treatment). One of these patients required resection of infundibular stenosis and closure of the foramen ovale at the age of four years, one is awaiting similar surgical treatment at the age of two years, in one case the recurrent obstruction was at valve level and responded to repeat balloon dilatation at age 15 weeks, and the fourth child remains well without further treatment. Repeat cardiac catheterisation was performed only in the three patients who required repeat balloon dilatation or surgery. There have been no late deaths.

\section{Discussion}

Surgical valvotomy without cardiopulmonary bypass, with or without an aortopulmonary shunt, is the conventional treatment for pulmonary atresia with intact ventricular septum and a tripartite right ventricle. Results of surgical treatment in different centres have varied enormously, some studies concluding that valvotomy alone very rarely proves effective in decompressing the right ventricle ${ }^{5}$ and others suggesting that valvotomy alone may be effective and a shunt may prove unnecessary if prostaglandin $\mathrm{E}$ treatment is continued for prolonged periods after valvotomy. ${ }^{6}$ Early operative mortality has been reported to be between $43 \%^{7}$ and $3 \%{ }^{8}$

The major factor in deciding on a patient's suitability for treatment by valvotomy alone is the morphology of the right ventricle and, in particular, its potential capability to support the pulmonary circulation without an aortopulmonary shunt. There continues to be much debate on the best method of assessing right ventricular morphology; there are proponents of using complex scoring of right ventricular size (the $\mathrm{Z}$ value), ${ }^{9}$ a simple measurement of tricuspid annulus diameter, ${ }^{10}$ or merely visual assessment of how well formed the right ventricular infundibulum appears to be. ${ }^{8}$ The latter, simplest, approach (not dissimilar to our own) appears to have produced the most rewarding results. ${ }^{8}$ Even in series selected for relatively favourable right ventricular morphology (that is, suitable for a surgical valvotomy without a shunt), operative mortality has been reported to be as high as $25 \% .{ }^{11}$ Early experience of valvotomy using a balloon introduced surgically through the right ventricular apex suggested that balloon dilatation was as effective as conventional closed valvotomy..$^{12}$

The first report of transcatheter laser valvotomy for pulmonary atresia ${ }^{1}$ assessed the potential of the technique in unselected patients with pulmonary atresia (both with and without ventricular septal defect). It was clear that perforation of the pulmonary valve and subsequent balloon dilatation was technically possible. Major complications such as perforation of the right ventricular outflow tract and femoral artery damage were encountered, with low body mass, infundibular atresia, or severe right ventricular hypoplasia being particular risk factors. Our results suggest that the technique is likely to be free from major complications if patients are carefully selected for relatively favourable right ventricular anatomy.

Table 2 Details of the eight patients who had successful laser valvotomy

\begin{tabular}{|c|c|c|c|c|c|c|c|}
\hline Patient & $\begin{array}{l}\text { Age at } \\
\text { valvotomy } \\
\text { (days) }\end{array}$ & $\begin{array}{l}\text { Weight at } \\
\text { valvotomy } \\
\text { (kg) }\end{array}$ & $\begin{array}{l}\text { RVOT flow } \\
\text { velocity after } \\
\text { duct closure }(\mathrm{m} / \mathrm{s})\end{array}$ & $\begin{array}{l}\mathrm{O}_{2} \text { saturation } \\
\text { after duct } \\
\text { closure }(\%)\end{array}$ & $\begin{array}{l}\text { Latest follow } \\
\text { up (days } \\
\text { after laser) }\end{array}$ & $\begin{array}{l}\text { Latest } \\
R V O T \text { flow } \\
\text { velocity }(\mathrm{m} / \mathrm{s})\end{array}$ & $\begin{array}{l}\text { Latest } \mathrm{O}_{2} \\
\text { saturation (\%) }\end{array}$ \\
\hline $\begin{array}{l}1 \\
2 \\
4 \\
5 \\
6 \\
7 \\
8 \\
9\end{array}$ & $\begin{array}{c}1 \\
4 \\
19 \\
70 \\
8 \\
5 \\
2 \\
0.5\end{array}$ & $\begin{array}{l}2 \cdot 1 \\
3 \cdot 3 \\
3 \cdot 6 \\
4 \cdot 7 \\
3 \cdot 6 \\
3 \cdot 6 \\
4 \cdot 3 \\
2 \cdot 7\end{array}$ & $\begin{array}{l}3 \cdot 2 \\
2 \cdot 5 \\
3 \cdot 8 \\
3 \cdot 2 \\
2 \cdot 6 \\
2 \cdot 0 \\
2 \cdot 0 \\
1 \cdot 4\end{array}$ & $\begin{array}{l}75 \\
95 \\
75 \\
80 \\
70 \\
70 \\
70 \\
50\end{array}$ & $\begin{array}{r}1720 \\
375 \\
135 \\
90 \\
70 \\
14 \\
107 \\
77\end{array}$ & $\begin{array}{l}3 \cdot 5^{\star} \\
3 \cdot 2 \\
2 \cdot 5^{\star} \\
3 \cdot 2^{\star} \\
4 \cdot 5^{\star} \\
2 \cdot 0 \\
2 \cdot 0 \\
1 \cdot 2\end{array}$ & $\begin{array}{l}80 \\
\text { Not measured } \\
97 \\
\text { Not measured } \\
83 \\
81 \\
\text { Not measured } \\
75\end{array}$ \\
\hline
\end{tabular}

*Patients 1 and 4 had repeat balloon dilatation of the pulmonary valve at 19 days and 15 weeks. Patient 1 has now undergone surgical relief of infundibular stenosis with closure of the foramen ovale (at 4 years) and patient 6 is awaiting similar surgery. RVOT, right ventricular outflow tract. 


\section{PRACTICAL TECHNIQUE}

Our approach to laser valvotomy was simpler than the technique originally described. ${ }^{1} \mathrm{We}$ found that arterial catheterisation could be avoided in all our patients. Left ventriculography provided sufficient detail of pulmonary trunk anatomy in every case and we found that a guidewire positioned either in the pulmonary artery or across the duct provided sufficient support for balloon dilatation without the creation of a wire "circuit" through the heart. This simpler technique is likely to reduce morbidity such as arterial damage and ductal spasm.

Although some patients required more than one laser firing, the laser wire provided very rapid perforation of the valve in the majority of cases, with a minimum of force required to advance the wire into the pulmonary trunk. This is in contrast to other techniques such as radiofrequency ${ }^{13}$ perforation of the valve, when prolonged heating of the wire tip may be necessary before perforation is achieved. We believe the laser wire, which behaves very much like a standard guidewire, is superior to the presently available radiofrequency wires which provide little support for a balloon catheter after valve perforation. It has been suggested that the sharp end of a guidewire may be all that is required to perforate an atretic pulmonary valve. ${ }^{14}$ Our own attempts to perforate the valve with a guidewire alone (before laser and radiofrequency wires were available) were unsuccessful and in stark contrast to our experience with laser valvotomy.

FOLLOW UP

None of our patients who had successful laser valvotomy required a surgical shunt. We believe that patience in the early weeks after valvotomy is vital and that prolonged prostaglandin $\mathrm{E}$ treatment in those patients who remain duct dependent will usually allow right ventricular hypertrophy to regress and pulmonary blood flow to increase, such that an aortopulmonary shunt is avoidable in this selected group of patients. Even after prostaglandin E was withdrawn, we saw continued improvement in oxygen saturation in all our patients over a period of some months.

It is clear that right ventricular outflow obstruction may recur or become progressively more severe after successful laser valvotomy and balloon valvoplasty. Although this is likely to be due to infundibular hypertrophy, recurrent valve stenosis may also occur, and if this is the case repeat balloon valvoplasty may be the only further treatment required.

\section{CONCLUSIONS}

Laser valvotomy followed by balloon valvoplasty is both safe and effective if patients are carefully selected for the procedure, and we recommend it as the treatment of choice.

Even patients selected for their favourable $\stackrel{\varrho}{=}$ anatomy may require surgical attention in $\overrightarrow{\vec{z}}$ some form at a later stage. The avoidance of $\stackrel{\vec{D}}{\sigma}$ surgically induced scarring may have the added benefit of reducing morbidity in those $\frac{\bar{O}}{\bar{N}}$ patients who do prove to require surgery (for instance closure of the atrial septum or relief $\Omega$ of infundibular pulmonary stenosis) when they are older.

We are grateful to Dr Christopher Wren and Dr Edmund Ladusans for permission to report patients under their care.

1 Qureshi SA, Rosenthal E, Tynan M, Anjos R, Baker E. Transcatheter laser assisted pulmonic valve dilatation in pulmonic valve atresia. Am $\mathcal{F}$ Cardiol 1991;67:428-31

2 Rosenthal E, Qureshi SA, Kakadekar AP, Anjos R, Baker EJ, Tynan $M$. Technique of percutaneous laser-assisted i valve dilatation for valvar atresia in congenital heart dis- $\mathcal{O}$ ease. Br Heart f 1993;69:556-62.

3 Parsons JM, Rees MR, Gibbs JL. Percutaneous laser valvo- 을 tomy with balloon dilatation of the pulmonary valve as primary treatment for pulmonary atresia. Br Heart $\mathcal{F}$ 1991;66:36-8.

4 Salmon AP, Keeton BR, Sethia B. Developments in interventional cardiac catheterisation and progress in surgery $\frac{\Omega}{\supset}$ for congenital heart disease: achieving a balance. Br Heart f 1993;69:479-80.

5 Bull C, Kostelka M, Sorensen K, de Leval M. Outcome measures for the noenatal management of pulmonary. atresia with intact ventricular spetum. $f$ Thorac Cardiovasc Surg 1994;107:359-66.

6 Steinberger J, Berry JM, Bass JL, Foker JE, Braunlin EA, Krabill KA, et al. Results of a right ventricular outflow patch for pulmonary atresia with intact ventricular septum. Circulation 1992;86(suppl 5):167-75.

7 Leung MP, Mok CK, Lee J, Lo RN, Cheung H, Chiu C. Management evolution of pulmonary atresia and intact ventricular septum. Am f Cardiol 1993;71:1331-6.

8 Pawade A, Capuani A, Penny DJ, Karl TR, Mee RB. Pulmonary atresia with intact ventricular septum: surgical management based on right ventricular infundibulum. $\mathcal{F}$ Cardiac Surg 1993;8:371-83.

9 Hanley FL, Sade RM, Blackstone EH, Kirklin JW, Freedom RN, Nanda NC. Outcomes in neonatal pul- $\vec{D}$ monary atresia with intact ventricular septum. A multiinstitutional study. F Thorac Cardiovasc Surg 1993;105: 406-23.

10 Alboliras ET, Julsrud PR, Danielson GK, Puga FJ, Schaff HV, McGoon DC, et al. Definitive operation for pulmonary atresia with intact ventricular septum. Results in twenty patients. I Thorac Cardiovasc Surg 1987;93: 454-64

11 Leung MP, Lo RN, Cheung H, Lee J, Mok CK. Balloon 윽 valvuloplasty after pulmonary valvotomy for babies with pulmonary atreisa and intact ventricular septum. Ann Thorac Surg 1992;53:864-70.

12 Hamilton JR, Fonseka SF, Wilson N, Dickinson DF, Walker DR. Br Heart $\mathcal{F}$ 1987;58:374-7.

13 Rosenthal E, Qureshi SA, Chan KC, Martin RP, Skehan DJ, Jordan SC, et al. Radiofrequency assisted balloon $N$ dilatation in patients with pulmonary atresia and an intact ventricular septum. Br Heart F 1993;69:347-51.

14 Gournay V, Piechaud JF, Delogu A, Sidi D, Kachaner J. O Balloon valvotomy for critical stenosis or atresia of pulmonary valve in newborns. F Am Coll Cardiol 1995;26: 1725-31. 